DigiTALCOMMONS

— @WAYNESTATE-
Michigan Journal of Counseling:

Research, Theory and Practice

Volume $31 \mid$ Issue 1

Article 5

$2-1-2003$

\title{
Group Counseling for the Family Caregivers of Alzheimer's Clients: An Existential Approach
}

Jason McGlothlin

Kent State University, jmcgloth@kent.edu

Scott E. Hall

University of Dayton

Follow this and additional works at: https://digitalcommons.wayne.edu/mijoc

\section{Recommended Citation}

McGlothlin, J., \& Hall, S. E. (2003). Group Counseling for the Family Caregivers of Alzheimer's Clients: An Existential Approach, Dimensions of Counseling, 31(1), 25-31. doi:10.22237/mijoc/1044057840

This Article is brought to you for free and open access by the Open Access Journals at DigitalCommons@WayneState. It has been accepted for inclusion in Michigan Journal of Counseling: Research, Theory and Practice by an authorized editor of DigitalCommons@WayneState. 


\section{Group Counseling for the Family Caregivers of Alzheimer's Clients: An Existential Approach}

\author{
Jason McGlothlin, Ph.D. \\ Kent State University \\ Scott E. Hall, Ph.D. \\ University of Dayton
}

\section{Introduction}

Three of the main concerns of existentialism, according to Stevenson (1974), are being an individual, having meaning in life, and having freedom. For the caregivers of Alzheimer's clients, these existential concerns may be easily lost due to the great amount of time and emotional energy that are required of them. The purpose of this article is to provide an existential approach to group counseling that supports and assists caregivers of clients with Alzheimer's. Presented is a brief look at the nature of Alzheimer's Disease, relevant findings on stress levels and emotional states of family members who take care of clients with Alzheimer's, several key concepts of the existential approach to group counseling, and lastly some tips for group leaders.

\section{The Nature of Alzheimer's Disease}

According to the Diagnostic and Statistical Manual of Mental Disorders IVText Revised (DSM-IV-TR) (American Psychiatric Association, 2000), approximately $2 \%$ to $4 \%$ of the population suffer from Dementia of the Alzheimer's Type (for the purposes of this article, Dementia of the Alzheimer's Type is called

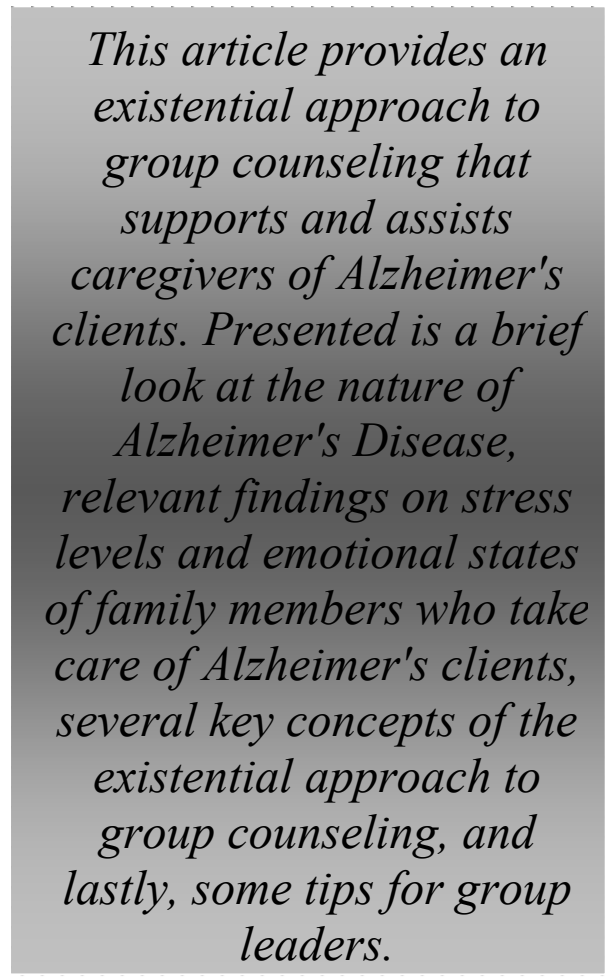

Correspondence concerning this manuscript should be addressed to Jason McGlothlin, Counseling and Human Services, 310 White Hall, Kent State University, Kent, Ohio 44242. imcgloth@kent.edu 
Alzheimer's). The DSM-IV-TR goes on to population state that this disorder is the result of a multitude of cognitive problems that are hallmarked by memory impairment along with other cognitive disturbances such as aphasia, apraxia, and agnosia. Onset of this disorder is considered to be early if it occurs before the age of 65 . The average duration of the illness is approximately eight to ten years from onset to death. During these years, the cognitive problems become progressively more debilitating and behavioral problems may also arise.

The apparent cognitive and behavioral problems of Alzheimer's cause great distress, guilt, and emotional strain for the family members who take care of individuals with Alzheimer's. Those Alzheimer's related behaviors that are found to cause the family caregiver the most stress are trouble sleeping, delusions, aggressiveness, agitation, and incontinence (Savorani, Vulcano, Boni, Sarti, \& Ravaglia, 1998).

\section{The Family Caregiver of Alzheimer's Clients (FCA)}

Persons are afflicted with Alzheimer's require a great amount of support and assistance from a wide variety of caregivers. Although there are many commonalities among the various types of caregivers (psychiatric nurses, activity therapists, day care workers, nursing home staff, and other professional medical and mental health professionals), the family caregivers of clients with Alzheimer's or FCAs are different because they have known and loved the client longer and knew them preonset of the disease.

Haley (1997) stated that FCAs portray an invaluable and essential role in the overall well-being of clients with Alzheimer's. In fulfilling this highly important role, the FCA's stress level and increasing responsibilities may result in a wide variety of mental and physical problems. When compared with caregivers of people with other disorders, such as Parkinson's Disease, the FCAs have a significantly higher number of mental health problems (Hooker et. al., 1998). Vetter et al. (1999) found that those with Alzheimer's impose greater stress on family members during the later and more severe stages of the disorder. In turn, counseling is best addressed and shows the most positive results during the early stages of Alzheimer's (Mittelman, 1995).

Ford et al. (1997) conducted a study comparing FCA gender and stress levels and found that male and female caregivers did not differ in the amount of time care giving each week and the stress level associated with their role as caregiver. Their study did reveal that the memory problems and difficulties with taking care of themselves were viewed as less stressful by males in this study, while dangerous behaviors and agitation were viewed by both genders as being the most stressful. Haley (1996) conducted another study on ethnicity and the emotional states of the FCAs and found that African American family members reported less depression when compared to Caucasian family members. This difference could be attributed to varying levels of familiar, social and community support.

In a study by Teri (1997), a positive correlation was found between the amount of stress/depression of the caregiver and the occurrence of depression in Alzheimer's. Shaw et al. (1997) reported that as clients with Alzheimer's progressed, their FACs tended to have a greater risk of serious illness. It also was found that the severity of Alzheimer's had a direct cascading effect on the family member's well-being (Lieberman $\&$ Fisher, 1995). With the varying stressors, emotional states, and impending concerns of death by the clients with Alzheimers and 
FACs, an existential group approach toward treating FACs may be one viable option.

\section{Existential Concepts when Applied to Caregivers in a Group Setting}

Spira (1997) reported that existential group counseling for those dealing with serious illnesses assists them with coping and adjusting to their illness while assisting them to live their lives more fully in the time they have left. Farran (1997) went further and specifically related existential group counseling concepts to the FCAs. Farran presented many positive aspects of existential group counseling including the issues of death and dying and the meaning of life.

Existential group counseling has its roots in the notion that human beings have free will and also have the option to make choices in life. When making choices, it is important to understand that some life events are totally irrational and without a cause, therefore suggesting that individuals are at times powerless in these situations. Even in these instances, though, existentialists believe that choices still can be made (Corey, 1995; Frankl, 1988; \& Yalom, 1980). These aspects of existentialism in group counseling relate to family caregivers of Alzheimer's clients who feel powerless and without options and choices.

Existential Anxiety. According to Yalom (1980), the feeling of anxiety is a basic characteristic common to all human beings. This anxiety is a result of having to make choices while being unaware of the outcomes. When dealing with existential anxiety, the group leader is to encourage members to accept their anxiety and view it as a feeling to promote growth. This existential anxiety must be worked through in ways that involve the recognition of needing others and the self, feeling guilt, being aware of lack of a meaning in life, and feeling burdened due to responsibilities and others' expectations (Corey, 1995; Yalom, 1980).

The FCAs elicit many common existential anxieties that may be due to the anticipated decrease in functioning and unanticipated behavioral outbursts of their loved ones. In addition, this existential anxiety may be seen through various physical symptoms such as high blood pressure (Shaw et al., 1999). A key in helping FACs recognize the signs of existential anxiety is creating self awareness.

Self Awareness. Corey (1995) and Yalom (1980) stated that the basic goal of existential group counseling is to expand the awareness of the self. Therefore, assisting group members to be aware that they are unique individuals with their own current feelings, while not reverting to past unwanted behaviors is crucial. If this awareness is achieved, it may help persons with FCA's to keep an open mind.

Seltzer, Vasterling, Yoder, and Thompson (1997) suggested that selfawareness is important in diminishing many of the burdens and worries of the FCAs. Seltzer (1997) added that self-awareness along with the awareness of the subtleties of their family members with Alzheimer's also may be beneficial. Schmall and Cleland (1989) indicated that an essential portion of the positive growth of caregivers includes understanding and accepting their feelings while being able to view these feelings as normal human responses.

Life and Death. The existential notion of death does not only apply to the termination of life but also the ending of situations and relationships in life. These endings in life must take place to allow for growth in new and more meaningful ways (Yalom, 1980). Bugental (1973) suggested that FCA group members must confront the meaningfulness 
of their loved one's deaths. He also suggested that group members may confront death by drawing a life line, thinking about the impact of their death, and writing obituaries to name only a few. The notion of dying (termination of life) is a frequent theme in group counseling sessions with FCA's because FCA's continually see their loved one with Alzheimer's diminish both physically and emotionally (Murphy, Hanrahan, \& Luchins; 1997).

Loos and Bowd (1997) also noted that FCAs experience endings or deaths other than the physiological death of their loved ones. Such deaths include the loss of social and recreational interaction, the death of their own well-being, and the loss of their career. These "deaths" result from FACs' great emotional and physical involvement and their perceived responsibility to the family member with Alzheimer's.

Meaningfulness and Meaninglessness. Two goals of existential counseling are to help clients (1) create meaning in life and (2) diminish aspects of their life that are meaningless. Questions such as Who am I? Where am I going? are necessary because life itself does not have positive meaning. The individual has to create meaning in life (Corey, 1995; Frankl, 1988 \& 1984; Holt, 1990; Yalom, 1980). Farran (1991) conducted a qualitative study using existential theory in the treatment of FCAs. Farran stated that an existential approach provides a different way of looking at and understanding experiences as a caregiver. Also, helping clients find meaningful relationships and maintaining these relationships are a key task for counselors dealing with FCAs (Schmall \& Cleland, 1989; Zanetti et. al. 1998).

Search for Authenticity. Being authentic and true to one's self is of great import to existentialists. According to Corey (1995) and Yalom (1980), being authentic means that one must risk becoming the person that he or she is capable of becoming. Being authentic also requires that one actively participate in life while making commitments. Wasow (1986) indicated that the issue of authenticity is a prevalent issue in counseling groups for FCAs. Authenticity arises when group members know that they are meeting the needs and pleasing the self rather than others. FCAs must therefore recognize that they have independent needs and coping mechanisms of their ailing family members.

\section{Existential Isolation and Relationships with} Others. Yalom (1980) stated that existentialists believe that persons must accept the fact that they are ultimately alone. Only by accepting this existential view can they then relate to others in a meaningful and genuine manner. FCAs must first establish a sense of a unique self or authenticity, which is typically difficulty for FCA's to accomplish due to the high demands placed on them by their ailing loved ones. To begin this process of relating to others, Schmall and Cleland (1989) stated that it is important for FCAs to ask for and accept help from others, which greatly reduces stress in and of itself. In addition, Speice, Shields, and Blieszner (1998) suggested that counselors should encourage FCAs to establish a more collaborative relationship with other group members, thus creating a cohesive group and an atmosphere of sharing commonalities.

Responsibility and the Willingness to Take Action. Existential theory suggests that individuals are responsible for moving and altering their own lives. Thus, helping FCAs recognize their freedom to make choices can assist them in coping with existential anxieties (Corey, 1995; Frankl, 1988; Yalom, 1980). Corey (1995) stated that "when people come to believe that they can direct their own destiny, they assume control 
over their lives" (p. 241). Therefore, the job of the group leader is to encourage members to take responsibility for their acts and contributions to their lives and to the group as a whole (Corey, 1995; Yalom, 1980).

FCAs are seen as responsible for their loved one's daily care. However the existential concern for the FCAs is: Are they willing to take responsibility and action for themselves? Schmall and Cleland (1989) stated that family caregivers need to keep expectations, commitments, and choices realistic. This need to take care of themselves is a common concern in group counseling with FCAs. Therefore, in the next section of this article, several suggestions for FCA group leaders regarding existential issues and self-care are presented.

\section{Suggestions for Group Leaders}

According to May (1983), the existential group leader, unlike other theoretical leaders, does not use a specific battery of techniques. Rather, the existential group leader relies on how the group members are simply being or what they are experiencing in their subjective world at the present moment. Corey (1995) added that specific techniques are not needed in existential group counseling because tasks are accomplished through the relationship and though perceived understanding between the group leader and the group member, and among group members. These relationships, in turn, create change, group cohesion, and an opportunity for all members and the leader to authentically experience life.

This is not to say that the existential group counseling process does not include the use of any techniques. On the contrary, the existential group leader may choose from a variety of techniques from other therapeutic approaches and theories (Corey, 1995). One of the essential roles of the group leader in existentialism is to stress "being and becoming somebody" rather than "introducing techniques and doing something" (p. 254).

According to the existential approach toward group counseling, the group leader must be fully present in the session while also genuinely experiencing the client in the here-and-now. The leader must focus on the humanistic aspects of members along with their subjective world. For work to be accomplished, an open and appropriate client - counselor relationship must be present (Corey, 1995; Yalom, 1980)

With these aspects and the existential key concepts at hand, group counseling has been found to be an effective treatment for FCAs. Emotional support combined with education has been found to be the best form of group counseling in treating this population (Rabins, 1998) with a heavy emphasis on the expression of emotions, development of the self, and the relationship between group members and group leader (Bloomgarden \& Kaplan, 1997; Hinkle, 1991; Shaw, 1997). Wasow (1986) concluded that in addition the members of the group recognize and deal with resistance along having the right to be unique and have different opinions.

When conducting a group consisting of FCAs, the group leader needs to be skilled in the areas of death and dying, grief, stress coping skills, women's roles, and dealing with perceived stress. Lastly, knowledge about consequential issues of Alzheimer's (e.g., medical, legal, financial information, available diagnostic and psychosocial functioning assessments) may prove to be helpful. With this knowledge and counseling obtained during the early stages of caregiving, the enhancement of wellness and the FCA's ability to effectively deal with current and future difficulties may occur (Cummings et al., 1998; Hinkle, 1991).

Mullan (1992) suggested that the key to client change in an existential group is the 
spontaneous meetings of members. The existential counselor may want to encourage members to confront the contradictions in their lives (i.e., life vs. death) rather than relying on the counselor's interpretations. In addition, the existential group leader may want to assist the members in becoming more aware of their issues so that they can choose to change.

Johnson (1997) suggested that focusing on the existential dilemmas of group members may enhance motivation and decrease hopelessness, shame, and suicide ideation. These existential dilemmas can be elicited by offering group members the opportunity to express courage, tolerance, and love.

\section{Conclusion}

Throughout this article links between effective treatment for FCAs and the existential approach toward group counseling have been presented. Many key concepts of existential theory were applied to FCAs. The particular issues that FCAs cope with, watching the gradual deterioration of a loved one, armed with the relationship and care they have, is both a highly stressful role and one that lends itself very well to existential based interventions. The cohesiveness of a group format can serve as a therapeutic entity by providing members with support and validation from the commonalities shared by others. Even counselors who do not have an especially strong background in using existential theory in their practice can explore some possible existential topics when counseling FCAs.

\section{References}

American Psychiatric Association. (2000). Diagnostic and statistical manual of mental disorders $\left(4^{\text {th }}\right.$ ed., text revised). Washington, DC: Author.
Bloomgarden, J., \& Kaplan, F.F. (1997). Using visualization and art to promote ego development: An evolving technique for groups. Art Therapy: Journal of the American Art Therapy Association, 10 (4), 201-207.

Bugental, J. F. (1973). Confronting the existential meaning of "my death" through group exercises. Interpersonal Development, 4(3), 148-163.

Corey, G. (1995). Theory and practice of group counseling ( $4^{\text {th }}$ ed.). Pacific Grove, CA: Brooks/Cole Publishing Company.

Cummings, S.M., Long, J.K., Peterson-Hazan, S., \& Harrison, J. (1998). The efficacy of a group treatment model in helping spouses meet the emotional and practical challenges of early stage caregiving. Clinical Gerontologist, 20(1), 29-45.

Farran, C.J. (1991). Finding meaning: An alternative paradigm for Alzheimer's disease family caregivers. Gerontologist, 31(4), 483-489.

Farran, C.J. (1997). Theoretical perspectives concerning positive aspects of caring for elderly persons with Dementia: Stress/adaptation and existentialism. Gerontologist, 37(2), 250-256.

Ford, G. R., Goode, K.T., Barrett, J. J., Harrell, L. E., \& Haley, W. E. (1997). Gender roles and caregiving stress: An examination of subjective appraisals of specific primary stressors in Alzheimer's caregivers. Aging \& Mental Health, 1(2), 158-165.

Frankl, V.E. (1984). Man's search for meaning: An introduction to logotherapy. New York: Simon \& Schuster.

Frankl, V.E. (1988). The will to meaning. New York: Meridian Book.

Haley, W.E. (1997). The family caregiver's role in Alzheimer's disease. Neurology, 48(5), 25-29.

Hinkle, J. S. (1991). Support group counseling for caregivers of Alzheimer's disease patients. Journal for Specialists in Group Work. 16(3), 185-190.

Holt, H. (1990). Existential group analysis. In Kutash, I.L., \& Wolf, A. (Eds.). The group psychotherapist's handbook: Contemporary theory and technique. (pp. 175-190). New York: Columbia University Press.

Hooker, K., Monahan, D.J., Bowman, S.R., Frazier, L.D., \& Shifren, K. (1998). Personality counts for a lot: Predictors of mental and physical health of spouse caregivers in two disease groups. Journals of Gerontology: Series B: Psychological Sciences \& Social Sciences, 53B(2), 73-85.

Johnson, D.R. (1997). An existential model of group therapy for chronic mental conditions. International Journal of Group Psychotherapy, 47(2), 227-250.

Lieberman, M.A., \& Fisher, L. (1995). The impact of chronic illness on the health and well-being of family members. Gerontologist, 35(1), 94-102.

Loos, C., \& Bowd, A. (1997). Caregivers of persons with Alzheimer's disease: Some neglected 
implications of the experience of personal loss and grief. Death Studies, 21(5), 501-514.

May, R. (1983). The discovery of being: Writings in existential psychology. New York: Norton.

Mittelman, M. S. (1995). A comprehensive support program: Effect on depression in spousecaregivers of AD patients. Gerontologist, 35(6), 792-802.

Mullan, H. (1992). "Existential" therapists and their group therapy practices. International Journal of Group Psychotherapy, 42(4), 453-468.

Murphy K., Hanrahan P., \& Luchins D. (1997). A survey of grief and bereavement in nursing homes: the importance of hospice grief and bereavement for the end-stage Alzheimer's disease patient and family. Journal of the American Geriatrics Society, 45(9), 1104-1107.

Rabins, P. V. (1998). The caregiver's role in Alzheimer's disease. Dementia \& Geriatric Cognitive Disorders, 9(3), 25-28.

Savorani, G., Vulcano, V., Boni, S., Sarti, G., \& Ravaglia, G. (1998). Behavioral disorders in dementia patients and their impact on the stress of caregiving relatives: The "ARAD" questionnaire. Archives of Gerontology \& Geriatrics, 6, 481-485.

Schmall, V.L., \& Cleland, M. (1989). Helping memory-impaired elders: A guide for caregivers. A Pacific Northwest Extension Publication.

Seltzer, B. (Feb. 1997). Awareness of deficit in Alzheimer's disease: Relation to caregiver burden. Gerontologist, 37(1), 20-24.

Seltzer, B., Vasterling, J.J., Yoder, J., \& Thompson, K.A. (1997). Awareness of deficit in Alzheimer's disease: Relation to caregiver burden. Gerontologist, 37(1), 20-24.

Shaw, W.S., Patterson, T.L., Ziegler, M.G., Dimsdale, J.E., Semple, S.J., \& Grant, I. (1999). Accelerated risk of hypertensive blood pressure recordings among Alzheimer caregivers. Journal of Psychosomatic Research, 46(3), 215-227.

Shaw, W.S., Semple, S.J., Ho, S., Irwin, M.R., Hauger, R.L., Grant, I., \& Patterson, T.L. (1997). Longitudinal analysis of multiple indicators of health decline among spousal caregivers. Annals of Behavioral Medicine, 19(2), 101-109.

Speice, J., Shields, C.G., \& Blieszner, R. (1998). The effects of family communication patterns during middle-phase Alzheimer's disease. Families, Systems \& Health, 16(3), 233-248.

Spira, J.L. (1997). Existential group therapy for advanced breast cancer and other life-threatening illnesses. In Spira, J. L., (Ed.), Group therapy for medically ill patients, (pp. 165-222). New York: Guilford Press.
Stevenson, L. (1974). Seven theories of human nature $\left(2^{\text {nd }}\right.$ ed.). New York, NY: Oxford University Press.

Teri, L. (1997). Behavior and caregiver burden: Behavioral problems in patients with Alzheimer disease and its association with caregiver distress. Alzheimer Disease \& Associated Disorders, 11(4), S35-S38.

Wasow, M. (1986). Support groups for family caregivers of patients with Alzheimer's disease. Social Work, 31(2), 93-97.

Yalom, I.D. (1980). Existential psychotherapy. USA: Basic Books.

Zanetti, O., Frisoni, G.B., Bianchetti, A., Tamanza, G., Cigoli, V., \& Trabucchi, M. (1998). Depressive symptoms of Alzheimer caregivers are mainly due to personal rather than patient factors. International Journal of Geriatric Psychiatry, 13(6), 358-367. 